\title{
Risk factors for pneumonia among patients with Parkinson's disease: a Taiwan nationwide population-based study
}

This article was published in the following Dove Press journal:

Neuropsychiatric Disease and Treatment

27 April 2016

Number of times this article has been viewed

\author{
Yang-Pei Chang,' Chih- \\ Jen Yang, ${ }^{2}$ Kai-Fang Hu, ${ }^{3}$ \\ A-Ching Chao, ${ }^{4}$ Yu-Han \\ Chang, ${ }^{5}$ Kun-Pin Hsieh, ${ }^{6}$ Jui- \\ Hsiu Tsai, ${ }^{7}$ Pei-Shan Ho, ${ }^{8,9}$ \\ Shen-Yang Lim ${ }^{10}$ \\ 'Department of Neurology, \\ ${ }^{2}$ Department of Internal Medicine, \\ ${ }^{3}$ Department of Dentistry, Kaohsiung \\ Municipal Ta-Tung Hospital, \\ ${ }^{4}$ Department of Neurology, College \\ of Medicine, ${ }^{5}$ Department of \\ Management, Kaohsiung Municipal \\ Ta-Tung Hospital, ${ }^{6}$ School of Pharmacy, \\ College of Pharmacy, ${ }^{7}$ Department \\ of Psychiatry, Kaohsiung Municipal \\ Ta-Tung Hospital, ${ }^{8}$ Faculty of Dental \\ Hygiene, College of Dental Medicine, \\ Kaohsiung Medical University, ${ }^{9}$ Cancer \\ Center, Kaohsiung Medical University \\ Chung-Ho Memorial Hospital, \\ Kaohsiung, Taiwan, Republic of China; \\ ${ }^{10}$ Faculty of Medicine, University of \\ Malaya, Kuala lumpur, Malaysia
}

Correspondence: Jui-Hsiu Tsai Department of Psychiatry, Kaohsiung Municipal Ta-Tung Hospital, Kaohsiung Medical University, Shih-Chuan Ist Rd, Kaohsiung 807, Taiwan, Republic of China Tel +8867 29I I I0I ext 6822

Fax +88672911590

Email d880340@kmu.edu.tw

Pei-Shan Ho

Faculty of Dental Hygiene, College of Dental Medicine, Kaohsiung Medical University Hospital, Kaohsiung Medical University, Shih-Chuan Ist Rd, Kaohsiung 807, Taiwan, Republic of China

$\mathrm{Tel}+8867291 \quad$ II 01 ext 8913

Fax +886729I 1590

Email psho@kmu.edu.tw
Objective: Pneumonia is the leading cause of death in patients with Parkinson's disease (PD). However, few studies have been performed to explore the risk factors for pneumonia development in patients with PD.

Methods: We conducted a nationwide population-based cohort study of patients with PD to identify the risk factors for these patients developing pneumonia. Participants with newly diagnosed PD between 2000 and 2009 were enrolled from the 2000-2010 National Health Insurance Research Database in Taiwan. We compared patients with PD with an incidence of hospitalization with pneumonia vs those without, and Cox proportional hazard models were used to estimate the risk of pneumonia.

Results: Of the 2,001 enrolled patients (mean follow-up duration 5.8 years, range: $2.7-14.7$ years), 381 (19.0\%) had an incidence of hospitalization with pneumonia during the study period. Multivariate Cox proportional hazards analysis identified older age group ( $\geq 80$ years of age, hazard ratio $[\mathrm{HR}]=3.15$ [95\% confidence interval 2.32-4.28]), male sex (HR=1.59 [1.29-1.96]), certain geographic regions (northern, HR $=1.36$ [1.04-1.78], southern and eastern, HR =1.40 [1.05-1.88]), rural areas $(\mathrm{HR}=1.34$ [1.05-1.72]), chronic heart failure $(\mathrm{HR}=1.53$ [1.02-2.29]), and chronic kidney disease $(\mathrm{HR}=1.39$ [1.03-1.90]) as risk factors for hospitalization with pneumonia in patients with PD. However, treatment for dental caries was a protective factor (HR $=0.80[0.64-0.99])$.

Conclusion: The results of this study highlight risk factors that are associated with hospitalization with pneumonia, and, for the first time, suggest a link between treated dental caries and a diminished risk of hospitalization with pneumonia in patients with PD.

Keywords: pneumonia, Parkinson's disease, dental caries, chronic heart failure, chronic kidney disease

\section{Introduction}

Parkinson's disease (PD) is a common neurodegenerative disorder characterized by bradykinesia, rigidity, resting tremor, and postural instability. ${ }^{1,2}$ With progression of the disease, the response to levodopa decreases and various problems that are less dopa responsive (or dopa resistant) develop, such as cognitive dysfunction and speech and swallowing problems. ${ }^{3,4}$ Studies have documented a very high prevalence of oropharyngeal dysphagia in patients with $\mathrm{PD},{ }^{5}$ which predisposes to aspiration pneumonia. Pneumonia in turn is a major reason for hospitalization of patients with PD and it is the leading cause of mortality in patients with PD (in one prospective study accounting for $64 \%$ of deaths). ${ }^{6,7}$

Pneumonia is a very common infectious disease and is one of the ten leading causes of death in the world. ${ }^{8}$ Several risk factors for pneumonia in the general population, 
including chronic pulmonary disease, chronic heart failure, diabetes, chronic liver disease, chronic kidney disease, cochlear implants, cerebrospinal fluid shunts, splenic dysfunction, and HIV/AIDS, have been recognized. ${ }^{9-12}$ In PD, aspiration pneumonia is thought to be a multifactorial event, and aspiration alone is insufficient to cause pneumonia. Other important factors include alterations in the bacterial flora of the oropharynx, as well as impaired pulmonary clearance and host resistance. To our knowledge, however, there have been no populationbased studies exploring the risk factors for pneumonia in patients with PD. Thus, we conducted a cohort study of patients with PD to identify the risk factors associated with pneumonia using a nationwide longitudinal population-based database.

\section{Methods}

\section{Data source}

Data for this study were derived from the 2000-2010 National Health Insurance Research Database (NHIRD), developed and managed by the Taiwan National Health Insurance Program for research purposes. The Taiwan National Health Insurance Program, since its introduction in 1995, has provided approximately $99 \%$ of Taiwan residents with comprehensive and universal health care. ${ }^{13}$ We used one of the subsets of the NHIRD, composed of 1 million randomly selected subjects (constituting nearly $5 \%$ of the total Taiwan population) drawn in 2000. The NHIRD includes data on patients' demographic characteristics, diagnoses, and prescription claims (medication types, prescription dates, dosage, and duration supplied). The study was approved by the Institutional Review Board at Kaohsiung Medical University Hospital, and informed consent was waived by the Institutional Review Board because the data obtained from the NHIRD have been de-identified.

\section{Design and study population}

The PD cohort comprised patients who were newly diagnosed (between January 1, 2000 and December 31, 2009) based on the International Classification of Disease, Ninth Revision, Clinical Modification (ICD-9-CM) diagnostic criteria (ICD-9-CM code 332). Patients were diagnosed by neurologists and received antiparkinsonian medication(s) (levodopa and decarboxylase inhibitor, entacapone, bromocriptine, pergolide, cabergoline, ropinirole, pramipexole, amantadine, or selegiline) with at least three consecutive outpatient clinic visits, which were characterized as regular follow up. ${ }^{14}$ Exclusion criteria were as follows: age $<40$ years; dementia, psychosis, or stroke before the diagnosis of PD (because of the potential for diagnostic confusion with dementia with Lewy bodies or vascular parkinsonism); and patients having a pneumonia-related diagnosis before
PD diagnosis (Figure 1). We also identified patients with PD with dementia that occurred $\geq 1$ year after the diagnosis of $\mathrm{PD}$ (termed PD dementia; ICD-9-CM codes 290, 294.1, 331.0). ${ }^{1}$

\section{An incidence of hospitalization with pneumonia}

Cases were determined by claims for hospital admissions using the following pneumonia-related codes: principal diagnosis of pneumonia (codes 480 to 487.0 ) or principal diagnosis of acute respiratory failure (code 518.81) or septicemia (code 038 ) with pneumonia as a secondary diagnosis. ${ }^{15}$ All enrolled patients with PD were followed-up until one of the following events occurred: first-time pneumonia diagnosis, death, the end of follow-up in the medical records, or the end of 2010. The study flowchart is shown in Figure 1.

\section{Risk factors related to pneumonia}

We identified the inpatient and outpatient diagnosis files and prescription files of patients with PD before they were diagnosed with $\mathrm{PD}^{16}$ to ascertain their history of diabetes mellitus, alcoholism, chronic pulmonary disease, dental caries, periodontitis, osteoporosis, chronic heart failure, chronic kidney disease, rheumatoid arthritis, chronic liver disease, cancer, epilepsy, asplenia after operation, cerebrospinal fluid shunt, multiple sclerosis, sickle cell disease, celiac disease, and HIV/AIDS, using ICD-9-CM codes and/or anatomical therapeutic chemical classification system codes. ${ }^{9,14,17,18}$ Of note, we used the diagnosis of dental caries or periodontitis based on ICD-9-CM and anatomical therapeutic chemical codes and required at least three visits as a proxy for treated dental illness (Table S1).

\section{Statistical analysis}

The chi-square test and $t$-test were used to compare the demographic and clinical characteristics of patients with PD with, vs those without, pneumonia. The Kaplan-Meier method was used to estimate the probability of pneumonia. The Cox proportional hazards model was applied to analyze the effect of single and multiple covariates in predicting pneumonia development in patients with PD. All statistical analyses were performed with SAS Version 9.3 (SAS Institute, Cary, NC, USA). A $P$-value $<0.05$ was considered statistically significant.

\section{Results \\ Demographic and clinical characteristics of the study population}

After excluding subjects who did not meet the study criteria, a total of 2,001 patients with newly diagnosed 


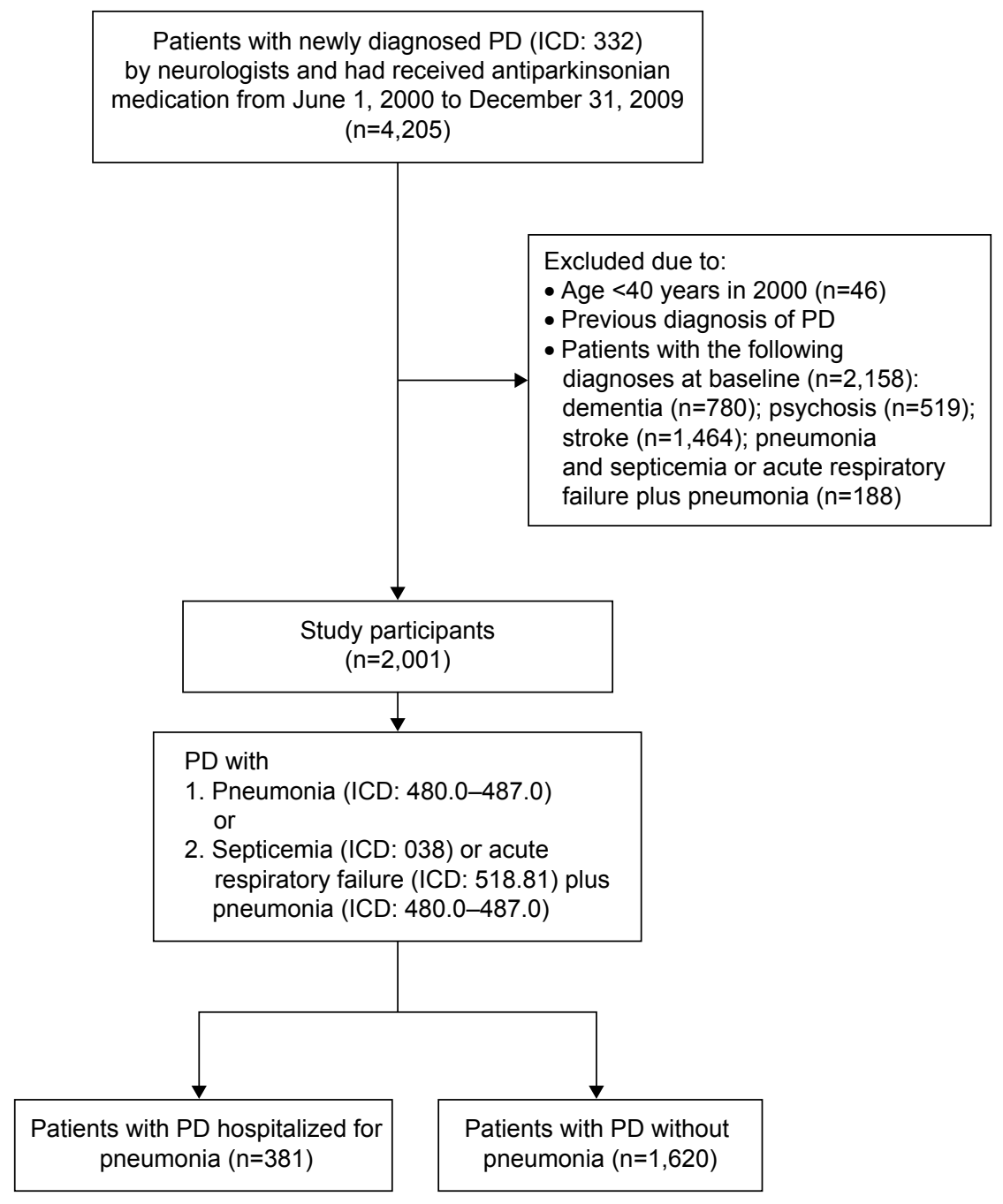

Figure I Flowchart of the study cohort assembly from medical records in Taiwan's National Health Insurance Research Database. Abbreviations: PD, Parkinson's disease; ICD, International classification of disease.

PD were identified. The mean duration of follow-up was 5.77 years \pm (standard deviation) 3.1 years. Of the 2,001 patients with PD, 381 (19.0\%) had an incidence of hospitalization with pneumonia, with a mean latency after PD diagnosis of $4.3 \pm 2.6$ years. Among the patients with PD in our study, several baseline characteristics were associated with the occurrence of pneumonia, including older age, male sex, geographic region of Taiwan (northern, southern, and eastern), lower income, fewer dental appointments, and also subsequent development of dementia (Table 1).

\section{Comorbid physical conditions in enrolled patients with PD}

After excluding dementia, psychosis, and stroke, the most common comorbid physical diseases were dental caries $(48.1 \%$ of enrolled patients), periodontitis (44.1\%), chronic pulmonary disease $(37.4 \%)$, diabetes mellitus
(25.6\%), and chronic liver disease (19.7\%) (Table 2). Comorbidities with a low incidence were cancer $(n=42)$, epilepsy ( $n=29)$, asplenia after operation $(n=4)$, cerebrospinal fluid shunt $(n=3)$, and multiple sclerosis $(n=3)$. There were no patients with sickle cell disease, celiac disease, or HIV/AIDS.

\section{Risk factors for pneumonia in the PD cohort (univariate Cox proportional hazards analysis)}

A univariate Cox proportional hazards analysis showed that patients with PD with chronic pulmonary disease, dental caries, chronic heart failure, and chronic kidney disease were at increased risk of developing pneumonia (Table 2). Multivariate Cox proportional hazards analysis identified the following as risk factors for pneumonia (Table 3): older age (70-79 years: hazard ratio [HR] $=2.12,95 \%$ confidence interval $[\mathrm{CI}] 1.64-2.75, P<0.001 ; \geq 80$ years: $\mathrm{HR}=3.15$, 
Table I Characteristics of patients with PD with and without pneumonia

\begin{tabular}{|c|c|c|c|}
\hline Patient characteristics & $\begin{array}{l}\text { Patients with PD with } \\
\text { pneumonia }(n=381)\end{array}$ & $\begin{array}{l}\text { Patients with PD without } \\
\text { pneumonia }(n=I, 620)\end{array}$ & $P$-value \\
\hline Age at enrolment, mean (SD), years & $74.78(7.46)$ & $70.16(9.17)$ & $<0.001$ \\
\hline Age group, years, n (\%) & & & $<0.001$ \\
\hline$<70$ & $90(23.6)$ & $719(44.4)$ & \\
\hline $70-79$ & $200(52.5)$ & $667(4 \mid .2)$ & \\
\hline$\geq 80$ & 91 (23.9) & $234(14.4)$ & \\
\hline Sex, n (\%) & & & $<0.001$ \\
\hline Male & $231(60.6)$ & $782(48.3)$ & \\
\hline Female & $150(39.4)$ & $838(51.7)$ & \\
\hline Geographic region of Taiwan, $n$ (\%) & & & 0.015 \\
\hline Central & $78(20.5)$ & $448(27.7)$ & \\
\hline Northern & $188(49.3)$ & $713(44.0)$ & \\
\hline Southern and Eastern & $115(30.2)$ & $459(28.3)$ & \\
\hline Urban level, n (\%) & & & 0.098 \\
\hline Urban and suburban & $276(72.4)$ & $\mathrm{I}, 103(68.1)$ & \\
\hline Rural & $105(27.6)$ & $517(31.9)$ & \\
\hline Monthly income, NT\$, n (\%) & & & $<0.001$ \\
\hline$\geq 30,000$ & $18(4.7)$ & $195(12.0)$ & \\
\hline$<30,000$ & $363(95.3)$ & $\mathrm{I}, 425(88.0)$ & \\
\hline Dental attendance rate, $\mathrm{n}(\%)$ & & & $<0.001$ \\
\hline No & $210(54.3)$ & $696(42.9)$ & \\
\hline Yes & $177(45.7)$ & $927(57.1)$ & \\
\hline PD with dementia, ${ }^{a} \mathrm{n}(\%)$ & $102(26.4)$ & $264(16.3)$ & $<0.001$ \\
\hline
\end{tabular}

Note: ${ }^{2}$ Dementia occurred at least I year after diagnosis of PD.

Abbreviations: PD, Parkinson disease; SD, standard deviation; NT\$, new Taiwan dollar.

95\% CI 2.32-4.28, $P<0.001)$; male sex (HR $=1.59,95 \%$ CI 1.29-1.96, $P<0.001$ ); geographic region of Taiwan (northern: HR $=1.36,95 \%$ CI 1.04-1.78, $P=0.024$; southern and eastern: $\mathrm{HR}=1.40,95 \%$ CI $1.05-1.88, P=0.023$ ); rural areas $(\mathrm{HR}=1.34,95 \% \mathrm{CI} 1.05-1.72, P=0.021)$; chronic heart failure (HR $=1.53,95 \% \mathrm{CI} 1.02-2.29, P=0.042)$; and chronic kidney disease $(\mathrm{HR}=1.39,95 \%$ CI $1.03-1.90, P=0.034)$. However, treatment for dental caries was a protective factor (HR $=0.80,95 \%$ CI $0.64-0.99, P=0.036$ ). Figure 2 shows the Kaplan-Meier analysis of the incidence of pneumonia in male and female patients with PD. Based on the analysis, we found similar patterns of pneumonia incidence in the male and female groups in the first 2 years after PD diagnosis; however, pneumonia incidence increased more rapidly in the male group during the follow-up period.

\section{Discussion}

To the best of our knowledge, this is the first study to identify risk factors for pneumonia in the PD population. This study used a nationwide population-based screening

Table 2 Comorbidities and risk of pneumonia - univariate Cox proportional hazards analysis

\begin{tabular}{|c|c|c|c|c|c|c|c|c|c|}
\hline $\begin{array}{l}\text { Comorbidities, } \\
\text { n (\%) }\end{array}$ & $\begin{array}{l}\text { Patients with PD } \\
\text { with pneumonia } \\
(n=381)\end{array}$ & $\begin{array}{l}\text { Patients with PD } \\
\text { without pneumonia } \\
(n=1,620)\end{array}$ & $P$-value & $\begin{array}{l}\text { Crude } \\
\text { HR }\end{array}$ & $(95 \% \mathrm{Cl})$ & $P$-value & $\begin{array}{l}\text { Adjusted } \\
\text { HR }\end{array}$ & $(95 \% \mathrm{Cl})^{\mathrm{a}}$ & $P$-value \\
\hline Diabetes mellitus & $90(23.6)$ & $423(26.1)$ & 0.317 & 1.20 & $(0.95-1.53)$ & 0.125 & 1.10 & $(0.86-1.40)$ & 0.438 \\
\hline Alcoholism & $37(9.7)$ & $150(9.3)$ & 0.785 & 1.35 & $(0.96-1.89)$ & 0.087 & 1.24 & $(0.88-1.75)$ & 0.229 \\
\hline $\begin{array}{l}\text { Chronic pulmonary } \\
\text { disease }\end{array}$ & $145(38.3)$ & $603(37.2)$ & 0.690 & 1.41 & $(1.14-1.73)$ & 0.001 & 1.14 & $(0.92-1.4 I)$ & 0.231 \\
\hline Dental caries & I4I (37.0) & $822(50.7)$ & $<0.001$ & 0.76 & $(0.6 \mathrm{I}-0.93)$ & 0.008 & 0.80 & $(0.64-0.99)$ & 0.036 \\
\hline Periodontitis & $134(35.2)$ & $748(46.2)$ & $<0.001$ & 0.83 & $(0.67-1.02)$ & 0.077 & 0.89 & $(0.69-1.14)$ & 0.339 \\
\hline Osteoporosis & $63(16.5)$ & $321(19.8)$ & 0.144 & 1.10 & $(0.84-1.44)$ & 0.499 & 1.12 & $(0.84-1.49)$ & 0.430 \\
\hline Chronic heart failure & $26(3.8)$ & $75(4.6)$ & 0.078 & 1.95 & $(I .3 I-2.9 I)$ & 0.001 & 1.53 & $(1.02-2.29)$ & 0.042 \\
\hline Chronic kidney disease & $48(12.6)$ & $180(11.1)$ & 0.411 & 1.60 & $(1.18-2.17)$ & 0.002 & 1.39 & $(1.03-1.90)$ & 0.034 \\
\hline Rheumatoid arthritis & $18(4.7)$ & $72(4.4)$ & 0.812 & 1.31 & $(0.82-2.11)$ & 0.260 & 1.26 & $(0.78-2.04)$ & 0.339 \\
\hline Chronic liver disease & $5 I(13.4)$ & $343(21.2)$ & 0.001 & 0.83 & $(0.62-1.12)$ & 0.215 & 0.77 & $(0.57-1.05)$ & 0.100 \\
\hline
\end{tabular}

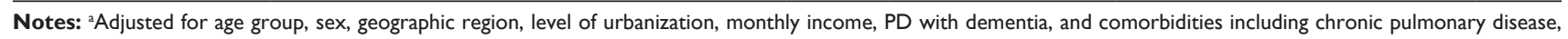
dental caries, chronic heart failure, and chronic kidney disease.

Abbreviations: PD, Parkinson's disease; HR, hazard ratio; CI, confidence interval. 
Table 3 Risk factors for pneumonia - multivariate Cox proportional hazards analysis

\begin{tabular}{|c|c|c|c|c|c|c|c|c|c|}
\hline \multirow[t]{2}{*}{ Risk factors } & \multirow{2}{*}{$\begin{array}{l}\text { Adjusted } \\
\text { HR }\end{array}$} & \multirow[t]{2}{*}{$(95 \% \mathrm{Cl})$} & \multirow[t]{2}{*}{$P$-value } & \multicolumn{3}{|c|}{ Female $(n=988)$} & \multicolumn{3}{|l|}{ Male $(n=I, 022)$} \\
\hline & & & & Adjusted HR & $(95 \% \mathrm{Cl})$ & $P$-value & Adjusted HR & $(95 \% \mathrm{Cl})$ & $P$-value \\
\hline \multicolumn{10}{|l|}{ Age group, years } \\
\hline$<70$ & 1.00 & - & - & 1.00 & - & - & 1.00 & - & - \\
\hline $70-79$ & 2.12 & $(1.64-2.75)$ & $<0.001$ & 2.69 & $(1.78-4.05)$ & $<0.001$ & 1.80 & $(1.28-2.52)$ & 0.001 \\
\hline$\geq 80$ & 3.15 & $(2.32-4.28)$ & $<0.001$ & 4.18 & $(2.56-6.84)$ & $<0.001$ & 2.57 & $(1.74-3.81)$ & $<0.001$ \\
\hline \multicolumn{10}{|l|}{ Sex } \\
\hline Female & 1.00 & - & - & - & - & - & - & - & - \\
\hline Male & 1.59 & $(1.29-1.96)$ & $<0.001$ & - & - & - & - & - & - \\
\hline \multicolumn{10}{|l|}{ Geographic region of Taiwan } \\
\hline Central & 1.00 & - & - & 1.00 & - & - & 1.00 & - & - \\
\hline Northern & 1.36 & $(1.04-1.78)$ & 0.024 & 1.42 & $(0.90-2.24)$ & 0.135 & 1.33 & $(0.95-1.86)$ & 0.096 \\
\hline Southern and Eastern & 1.40 & $(1.05-1.88)$ & 0.023 & 1.49 & $(0.92-2.43)$ & 0.105 & 1.34 & $(0.92-1.93)$ & 0.126 \\
\hline \multicolumn{10}{|l|}{ Urban level } \\
\hline Urban and suburban & 1.00 & - & - & 1.00 & - & - & 1.00 & - & - \\
\hline Rural & 1.34 & $(1.05-1.72)$ & 0.021 & $\mathrm{I} .43$ & $(0.96-2.14)$ & 0.078 & 1.33 & $(0.96-1.85)$ & 0.083 \\
\hline \multicolumn{10}{|l|}{ Monthly income, NT\$ } \\
\hline$\geq 30,000$ & 1.00 & - & - & 1.00 & - & - & 1.00 & - & - \\
\hline$<30,000$ & 1.50 & $(0.91-2.46)$ & 0.114 & 1.83 & $(0.45-7.52)$ & 0.400 & 1.57 & $(0.9 I-2.7 I)$ & 0.108 \\
\hline \multicolumn{10}{|l|}{ PD with dementia ${ }^{a}$} \\
\hline No & 1.00 & - & - & 1.00 & - & - & 1.00 & - & - \\
\hline Yes & 1.39 & $(0.92-2.10)$ & 0.114 & 1.51 & $(0.73-3.12)$ & 0.264 & 1.31 & $(0.79-2.17)$ & 0.290 \\
\hline \multicolumn{10}{|l|}{ Comorbidities } \\
\hline Chronic pulmonary disease & 1.14 & $(0.92-I .4 I)$ & 0.231 & 1.20 & $(0.84-I .7 I)$ & 0.313 & 1.15 & $(0.88-1.52)$ & 0.307 \\
\hline Dental caries & 0.80 & $(0.64-0.99)$ & 0.036 & 0.90 & $(0.64-1.27)$ & 0.548 & 0.74 & $(0.56-0.97)$ & 0.029 \\
\hline Chronic heart failure & 1.53 & $(1.02-2.29)$ & 0.042 & 2.22 & $(1.23-2.98)$ & 0.008 & 1.14 & $(0.64-2.03)$ & 0.649 \\
\hline Chronic kidney disease & 1.39 & $(1.03-1.90)$ & 0.034 & 1.03 & $(0.58-1.80)$ & 0.931 & 1.65 & $(1.13-2.39)$ & 0.009 \\
\hline
\end{tabular}

Note: a Dementia occurred at least I year after diagnosis of PD.

Abbreviations: PD, Parkinson's disease; HR, hazard ratio; Cl, confidence interval; NT\$, new Taiwan dollar.

of patients with PD to estimate the risk of hospitalization with pneumonia in Taiwan. A total of 2,001 patients with new-onset PD between 2000 and 2010 were identified in our cohort analysis. Overall, our study found that older age, male sex, geographic region of Taiwan, rural areas,

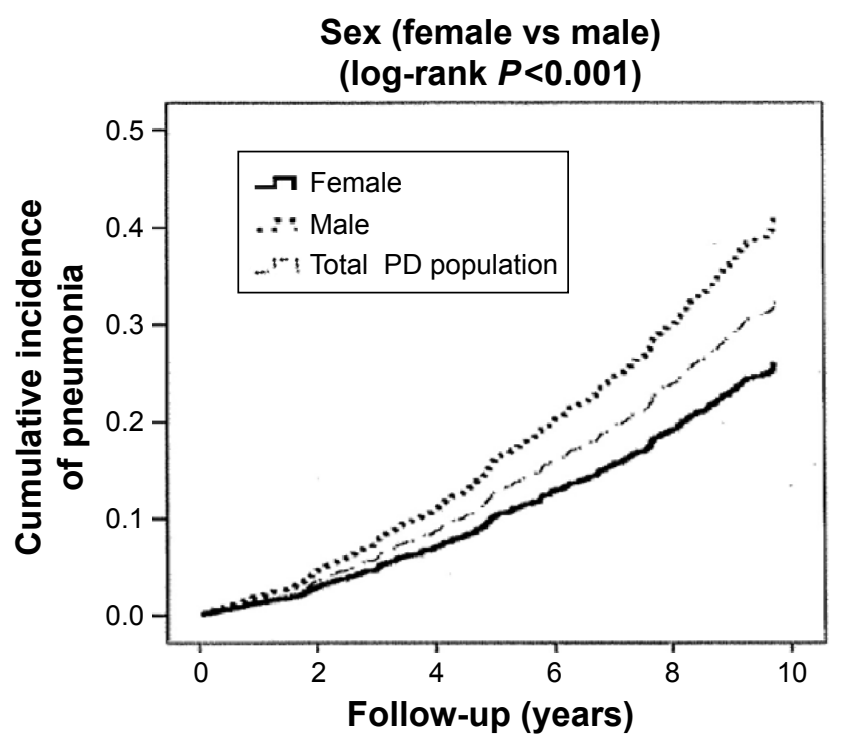

Figure 2 Kaplan-Meier analysis for incidence of pneumonia in patients with PD by sex. Abbreviation: PD, Parkinson's disease. chronic heart failure, and chronic kidney disease were independent risk factors for pneumonia among patients with PD. However, treatment for dental caries was a protective factor.

In general, the incidence of pneumonia in the general population increases with age, ${ }^{18-21}$ and is higher in males than in females. ${ }^{9,20}$ The demographics of our PD population in terms of age and sex were similar to those of the general population in these studies. Male patients with PD had a higher risk $(H R=1.59)$ of developing pneumonia (after adjusting for other confounding factors) than female patients. Although male vulnerability to pneumonia has long been recognized, and the consistency and magnitude of these differences between the sexes are particularly impressive in patients with interstitial pneumonia or ventilatorassociated pneumonia, ${ }^{22,23}$ the underlying mechanisms responsible for this phenomenon are still unclear. Our study found that the incidence of pneumonia among patients with PD was lower in central Taiwan and urbanized/ suburbanized regions. The results suggest that environmental factors may play a role in pneumonia risk in the PD population, and one possible reason may be a relative lack of access to health care resources. There is some literature reporting geographic differences in pneumonia incidence 
in the pediatric population, but this has not previously been observed in the PD population. ${ }^{21,24}$

Our study showed that chronic heart failure and chronic kidney disease are both independent predictive factors for pneumonia in patients with PD. Of all the comorbidities in this study, chronic heart failure had the largest magnitude as a risk factor for pneumonia $(\mathrm{HR}=1.53$ ) (and particularly in females aged $>80$ years old - Table S2), which is comparable to the twofold increased risk of pneumonia in the general population. ${ }^{25,26}$ Chronic kidney disease was associated with an increased risk of pneumonia among patients with PD in our study, similar to that in the general population, and this risk was particularly seen in older male patients. ${ }^{11,20}$ Although chronic pulmonary disease is recognized as an important risk factor for pneumonia in the general population, ${ }^{20}$ for reasons that are unclear, this did not emerge as a risk factor in our study.

Of interest, we found that patients with PD who had received treatment for dental caries suffered less from pneumonia (especially in males aged $<70$ years old) (Table S3). Poor oral health, including dental caries and periodontal diseases, is commonly observed in patients with PD, even in the early stages of the disease. ${ }^{27-29}$ The high prevalence of impaired swallowing, periodontal diseases, and caries may lead to a greater risk of aspiration pneumonia. ${ }^{30-33}$ Maintenance of good oral hygiene and control of oral biofilm formation in the elderly reduce the number of potential respiratory pathogens in the oral secretions, which in turn reduces the risk of pneumonia. ${ }^{34}$ Our findings suggest that patients with PD who received treatment for dental caries may have better oral health and a reduced risk of pneumonia than those who did not. Although we cannot determine based on the available data whether there were differences in dysphagia between the two groups, we believe our results highlight the potential importance of good oral health in reducing morbidity and mortality in patients with PD. In brief, patients with PD had similar risk factors for pneumonia hospitalization when compared to general population. Our study found that chronic heart failure, chronic kidney disease, and dental caries were more significant risk factors for pneumonia hospitalization among patients with PD.

The main strength of our study is that it provides information from a nationwide population-based cohort with a large sample size, and the results may provide a good representation of ethnic Chinese patients with PD. To increase the accuracy of the diagnosis of PD, the study population was obtained by linking an ambulatory care expenditures database (neurologists and ICD-9-CM code) and a prescription claims database (medical treatment for PD). Moreover, covariates, including common underlying diseases (especially dental illness), were taken into consideration. Nevertheless, there are some limitations in our study that deserve comment. First, the study was retrospective. We did not have the opportunity to review all the medical charts of patients from the de-identified National Institutes of Health database. Second, although we analyzed national health care records from a database of 1 million randomly selected subjects, there were still relatively few PD cases to allow us to make a more precise estimation of total PD populations in Taiwan. Third, information on other risk factors contributing to pneumonia, such as the severity of comorbidities, lifestyle factors, such as smoking and alcohol consumption, and biochemistry data were unavailable for retrieval from the database. Other lifestyle-related pneumonia risk factors, including contact with children and nutritional status, were not included in the study. Finally, it was difficult to distinguish between aspiration pneumonia and infectious pneumonia from the details available in the database.

\section{Conclusion}

Identification of risk factors for hospitalization with pneumonia among patients with PD in Taiwan has highlighted chronic heart failure, chronic kidney disease, and oral hygiene as being associated with an increased risk of pneumonia. In particular, older female patients with PD with chronic heart failure and older male patients with PD with chronic kidney disease had a significantly higher risk of pneumonia. In contrast, male patients with PD had a diminished risk of pneumonia if dental caries were treated previously. Early recognition and prompt management of comorbid physical diseases/risk factors in patients with PD may help to reduce the risk of hospitalization with pneumonia, and thus, the burden of the disease.

\section{Acknowledgments}

We thank the Taiwan NHRI and BNHI for providing data. The interpretation and conclusions contained in this article do not represent those of the NHRI and BNHI.

\section{Disclosure}

The authors report no conflicts of interest in this work.

\section{References}

1. de Lau LM, Breteler MM. Epidemiology of Parkinson's disease. Lancet Neurol. 2006;5(6):525-535.

2. Leibson CL, Maraganore DM, Bower JH, Ransom JE, O'brien PC, Rocca WA. Comorbid conditions associated with Parkinson's disease: a population-based study. Mov Disord. 2006;21(4):446-455. 
3. Scheife RT, Schumock GT, Burstein A, Gottwald MD, Luer MS. Impact of Parkinson's disease and its pharamacologic treatment on quality of life and economic outcomes. Am J Health Syst Pharm. 2000; 57(10):953-962.

4. Rodrigues B, Nóbrega AC, Sampaio M, Argolo N, Melo A. Silent saliva aspiration in Parkinson's disease. Mov Disord. 2011;26(1):138-141.

5. Kalf JG, de Swart BJ, Bloem BR, Munneke M. Prevalence of oropharyngeal dysphagia in Parkinson's disease: a meta-analysis. Parkinsonism Relat Disord. 2012;18(4):311-315.

6. Chen RC, Chang SF, Su CL, et al. Prevalence, incidence, and mortality of PD: a door-to-door survey in Ilan county, Taiwan. Neurology. 2001; 57(9):1679-1686.

7. Auyeung M, Tsoi TH, Mok V, et al. Ten year survival and outcomes in a prospective cohort of new onset Chinese Parkinson's disease patients J Neurol Neurosurg Psychiatry. 2012;83(6):607-611.

8. World Health Organization. The top 10 causes of death. Available from: http://www.who.int/mediacentre/factsheets/fs310/en/. Accessed May 1, 2014.

9. Vinogradova Y, Hippisley-Cox J, Coupland C. Identification of new risk factors for pneumonia: population-based case-control study. Br J Gen Pract. 2012;59(567):e329-e338.

10. Burman LA, Norrby R, Trollfors B. Invasive pneumococcal infections: incidence, predisposing factors, and prognosis. Rev Infect Dis. 1985; 7(2):133-142.

11. Linnemann CC Jr, First MR. Risk of pneumococcal infections in renal transplant patients. JAMA. 1979;241(24):2619-2621.

12. Bourgault AM, Van Scoy RE, Wilkowske CJ, Sterioff S. Severe infection due to Streptococcus pneumoniae in asplenic renal transplant patients. Mayo Clin Proc. 1979;54(2):123-126.

13. Cheng TM. Taiwan's National Health Insurance system: high value for the dollar. In: Okma KGH, Crivelli L, editors. Six Countries, Six Reform Models: The Health Reform Experience of Israel, the Netherlands, New Zealand, Singapore, Switzerland and Taiwan. Hackensack, NJ: World Scientific; 2009:71-204.

14. Lee $\mathrm{YC}$, Lin $\mathrm{CH}, \mathrm{Wu} \mathrm{RM}$, et al. Discontinuation of statin therapy associates with Parkinson disease: a population-based study. Neurology. 2013;81(5):410-416.

15. Chang GM, Tung YC. Factors associated with pneumonia outcomes: a nationwide population-based study over the 1997-2008 period. J Gen Intern Med. 2012;27(5):527-533.

16. Valderas JM, Starfield B, Sibbald B, Salisbury C, Roland M. Defining comorbidity: implications for understanding health and health services. Ann Fam Med. 2009;7(4):357-363.

17. Tsai CF, Liu CJ, Chen TJ, et al. Increased incidence of orthopedic fractures in cirrhosis patients: a nationwide population-base study. J Hepatol. 2013;58(4):706-714.

18. Torres A, Peetermans WE, Viegi G, Blasi F. Risk factors for communityacquired pneumonia in adults in Europe: a literature review. Thorax. 2013;68(11):1057-1065.

19. Dang TT, Eurich DT, Weir DL, Marrie TJ, Majumdar SR. Rates and risk factors for recurrent pneumonia in patients hospital with comminityacquired pneumonia: population-bases prospective cohort study with 5 years of follow-up. Clin Infect Dis. 2014;59(1):74-80.
20. Farr BM, Woodhead MA, Macfarlane JT, et al. Risk factors for community-acquired pneumonia diagnosed by general practitioners in the community. Respir Med. 2000;94(5):422-427.

21. Taylor JK, Fleming GB, Singanayagam A, Hill AT, Chalmers JD. Risk factors for aspiration in community-acquired pneumonia: analysis of a hospitalized UK cohort. Am J Med. 2013;126(11):995-1001.

22. Higashiguchi M, Kijima T, Sumikawa H, et al. A retrospective study of prognostic factors in patients with interstitial pneumonia receiving long-term oxygen therapy. Lung. 2014;192(5):729-737.

23. Sharpe JP, Magnotti LJ, Weinberg JA, et al. Gender disparity in ventilator-associated pneumonia following trauma: identifying risk factors for mortality. J Trauma Acute Care Surg. 2014;77(1):161-165.

24. Rudan I, Tomaskovic L, Boschi-Pinto C, Campbell H; WHO Child Health Epidemiology Reference Group. Global estimate of the incidence of clinical pneumonia among children under five years of age. Bull World Health Organ. 2004;82(12):895-903.

25. Wonodi CB, Deloria-Knoll M, Feikin DR, et al. Evaluation of risk factors for severe pneumonia in children: the Pneumonia Etiology Research for Child Health study. Clin Infect Dis. 2012;54 (Suppl 2): S124-S131.

26. Monteiro L, Souza-Machado A, Valderramas S, Melo A. The effect of levodopa on pulmonary function in Parkinson's disease: a systematic review and meta-analysis. Clin Ther. 2012;34(5):1049-1055.

27. Cicciù M, Risitano G, Lo Giudice G, Bramanti E. Periodontal health and caries prevalence evaluation in patients affected by Parkinson's disease. Parkinsons Dis. 2012;2012:541908.

28. Hanaoka A, Kashihara K. Increased frequencies of caries, periodontal disease and tooth loss in patients with Parkinson's disease. J Clin Neurosci. 2009;16(10):1279-1282.

29. Müller T, Palluch R, Jackowski J. Caries and periodontal disease in patients with Parkinson's disease. Spec Care Dentist. 2011;31(5): $178-181$.

30. Ortega O, Parra C, Zarcero S, Nart J, Sakwinska O, Clavé P. Oral health in older patients with oropharyngeal dysphagia. Age Ageing. 2014;43(1): $132-137$.

31. Oh E, Weintraub N, Dhanani S. Can we prevent aspiration pneumonia in the nursing home? J Am Med Dir Assoc. 2004;5(3):174-179.

32. Langmore SE, Terpenning MS, Schork A, et al. Predictors of aspiration pneumonia: how important is dysphagia? Dysphagia. 1998;13(2): 69-81.

33. Almirall J, Bolíbar I, Serra-Prat M, et al; Community-Acquired Pneumonia in Catalan Countries (PACAP) Study Group. New evidence of risk factors for community acquired pneumonia: a population-based study. Eur Respir J. 2008;31(6):1274-1284.

34. Scannapieco FA, Shay K. Oral health disparities in older adults: oral bacteria, inflammation, and aspiration pneumonia. Dent Clin North Am. 2014;58(4):771-782. 


\section{Supplementary materials}

Table SI ICD-9-CM codes and ATC classification system codes used in this study

\begin{tabular}{|c|c|}
\hline Main diseases & ICD-9-CM codes \\
\hline Parkinson disease & 332 \\
\hline Dementia & $290,294.1,331.0$ \\
\hline Stroke & $430-434,436-438$ \\
\hline Psychoses & 295,297 \\
\hline Pneumonia & $480.0,487.0$ \\
\hline Septicemia & 038 \\
\hline Acute respiratory failure & 518.81 \\
\hline Comorbidities & ICD-9-CM codes and ATC codes \\
\hline Diabetes mellitus & 249.XX-250.XX, 648.0I, 648.02, 588.I, 357.2 \\
\hline Alcoholism & $\begin{array}{l}291 . X X, 303.0 X, 303.9,305.00-305.02,571.0-571.5 \\
571.8-571.9,980.0,980.2,980.3,980.8,980.9,977.3, \text { VII.3 }\end{array}$ \\
\hline Chronic pulmonary disease & $416.8,416.9,490,49 \mid-495,496,500-505,506.4,508.1$ \\
\hline Dental caries & $\begin{array}{l}521.0,521.1,521.2,521.3,522.0,522.1,522.2,522.3,522.4 \text {, } \\
522.5,522.6,522.7,522.8,522.9 ; 89001 C-89005 C \text {, } \\
89008 C-89012 C, 89101 C-89105 C, 89108 C-89112 C, 89006 C \text {, } \\
90004 C, 90005 C, 90013 C, 90014 C, 90015 C, 90016 C, 90017 C \text {, } \\
92013 C, 92014 C, 92015 C, 92016 C, 92055 C\end{array}$ \\
\hline Periodontitis & $\begin{array}{l}523.0,523.1,523.2,523.3,523.4,523.5,523.8,523.9 ; 91001 C, \\
91003 \mathrm{C}, 91004 \mathrm{C}, 91006 \mathrm{C}-91008 \mathrm{C}, 91104 \mathrm{C}, \mathrm{P} 4001 \mathrm{C}, \mathrm{P} 40002 \mathrm{C} \text {, } \\
91009 \mathrm{~B}, 91010 \mathrm{~B}, 92027 \mathrm{C}, 92033 \mathrm{C}, 92071 \mathrm{C}, 91011 \mathrm{C}, 91012 \mathrm{C}, \\
91013 \mathrm{C}, 92013 \mathrm{C}, 92014 \mathrm{C}, 92015 \mathrm{C}, 92016 \mathrm{C}, 92055 \mathrm{C}\end{array}$ \\
\hline Osteoporosis & $733.0 \mathrm{X}$ \\
\hline Chronic heart failure & $\begin{array}{l}402.01,402.1 \mathrm{I}, 402.91,404.01,404.03,404.1 \mathrm{I}, 404.13,404.9 \mathrm{I}, \\
404.93,425.4,425.9,428.4 \mathrm{X}\end{array}$ \\
\hline Chronic kidney disease & $58 I-583,585-587$ \\
\hline Rheumatoid arthritis & $7|4.0,7| 4.1,7|4.2,7| 4.30-7|4.33,7| 4.4$ \\
\hline Chronic liver disease & 57I.40, 57।.4I, 57।.49, 57।.2, 57।.5, 57।.6, 572.2 \\
\hline Cancers & $140-208$ \\
\hline Epilepsy & $345 . X X, 649.40-649.44,780.3$ \\
\hline Asplenia after operation & $4|4.2,4| 4.3,4 \mid 5$ \\
\hline Cerebrospinal fluid shunt & $83049 B$ \\
\hline Multiple sclerosis & 340 \\
\hline Sickle cell or coeliac disease & 282.60 \\
\hline HIV/AIDS & $042,079.53,795.71$ \\
\hline Drug categories & ATC codes \\
\hline Levodopa & N04BA0I \\
\hline Levodopa and decarboxylase inhibitor & N04BA02 \\
\hline Levodopa, decarboxylase inhibitor, and COMT inhibitor & N04BA03 \\
\hline Entacapone & N04BX02 \\
\hline Bromocriptine mesylate & N04BC0I \\
\hline Pergolide mesylate & N04BC02 \\
\hline Cabergoline & N04BC06 \\
\hline Ropinirole & N04BC04 \\
\hline Pramipexole & N04BC05 \\
\hline Amantadine & N04BBOI \\
\hline Selegiline & N04BD0I \\
\hline
\end{tabular}

Abbreviations: ICD-9-CM, International Classification of Disease, Ninth Revision, Clinical Modification; ATC, anatomical therapeutic chemical. 

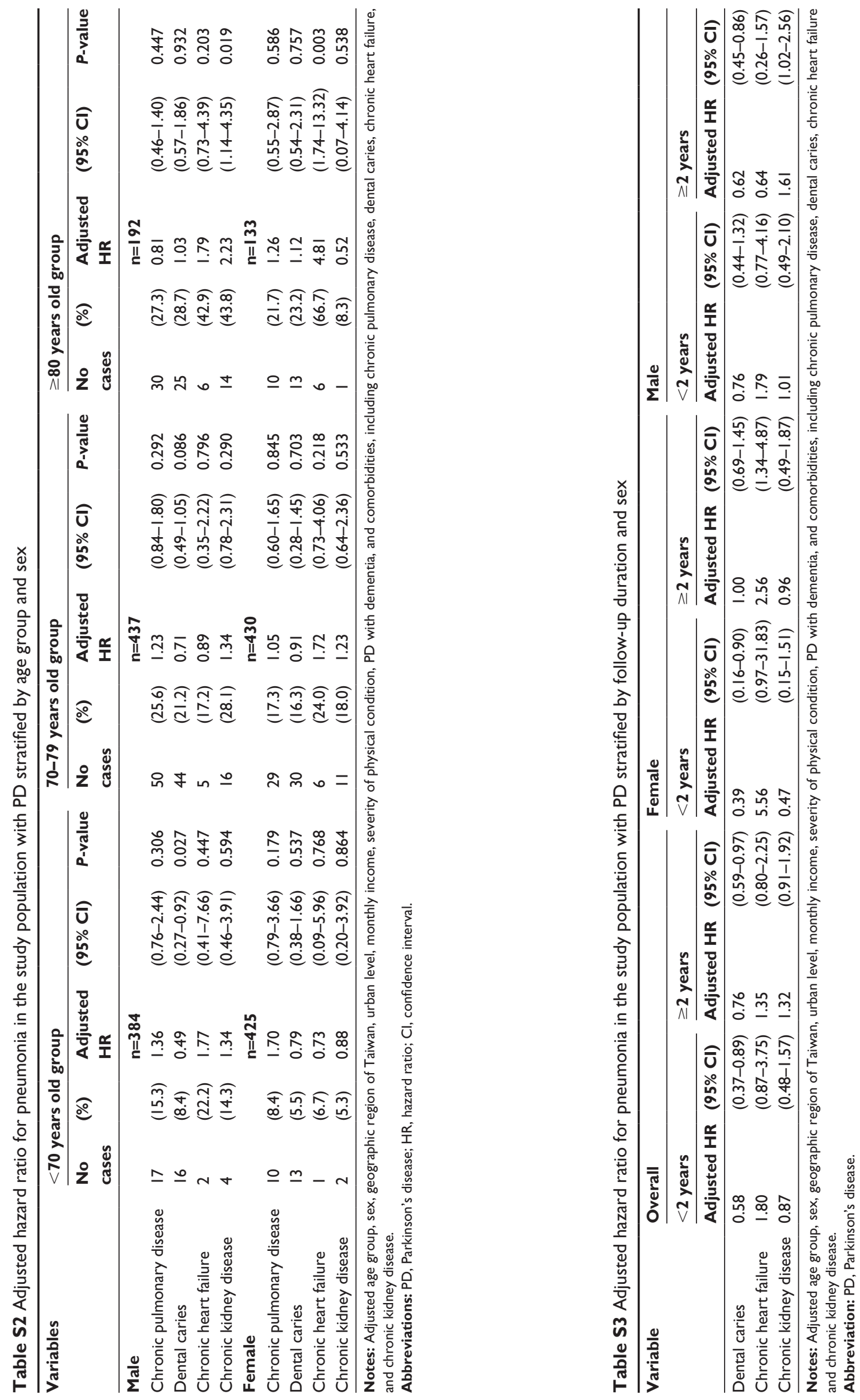


\section{Publish your work in this journal}

Neuropsychiatric Disease and Treatment is an international, peerreviewed journal of clinical therapeutics and pharmacology focusing on concise rapid reporting of clinical or pre-clinical studies on a range of neuropsychiatric and neurological disorders. This journal is indexed on PubMed Central, the 'PsycINFO' database and CAS, and is the official journal of The International Neuropsychiatric Association (INA). The manuscript management system is completely online and includes a very quick and fair peer-review system, which is all easy to use. Visit http://www.dovepress.com/testimonials.php to read real quotes from published authors.

\footnotetext{
Submit your manuscript here: http://www.dovepress.com/neuropsychiatric-disease-and-treatment-journal
} 